\title{
Numerical Investigation of a Liquid Gas Ejector
}

\author{
$1^{\text {st }}$ Daru Sugati ${ }^{1}, 2^{\text {nd }}$ Marwan Effendy $^{2}, 3^{\text {rd }}$ Sugiarto $^{3}$ \\ daru.tm@itny@ac.id ${ }^{1}$, Marwan.Effendy@ums.ac.id $^{2}$
}

\begin{abstract}
${ }^{1}$ Mechanical Engineering Department, Institut Teknologi Nasional Yogyakarta, Indonesia
${ }^{2}$ Mechanical Engineering Department, Universitas Muhammadiyah Surakarta, Indonesia

${ }^{3}$ Electrical Engineering Department, Institut Teknologi Nasional Yogyakarta, Indonesia
\end{abstract}

\begin{abstract}
This paper describes a numerical study of liquid jet gas ejector in a vacuum pump. An experimental model of liquid-gas ejector was used in this simulation study. The realisable $k-\varepsilon$ turbulence model was utilized in RANS simulation. Investigations were realised at various liquid velocities from $2-10 \mathrm{~m} / \mathrm{s}$ and remained constant gas velocity at $0.02 \mathrm{~m} / \mathrm{s}$. The CFD validated pressure is in good agreement with the available experimental data. The composition of gas and liquid is to be sensitive against the mixing process of liquid-gas in the throat section which cause the specific distribution of both pressure and velocity along the channel.

Keyword: Numerical Investigation, Liquid Gas Ejector
\end{abstract}

\section{Introduction}

In the food production process, the use of lower pressure is an effective way of producing the highest production quality. In order to prevent the potential damages during food processing the farmed commodity such as water melon always continues at both lower pressure and temperature. Typically in food production, a vacuum pump, such as the ejector type, are used. This type is often used because of low investment, high efficiency and easy maintenance.

The type of liquid-gas ejector is generally utilized in food processing, where fluid is used to trigger the spray in ejector. It is composed of a nozzle, suction chamber, throat (constant area duct) and diffuser. Various parameters, including a gas velocity, liquid suction chamber level, nozzle diameter, throat height and diameter on the liquid entrainment, the entrainment ratio $(\mathrm{L} / \mathrm{G})$ and the pressure drop play a significant role in driving gas-liquid ejector performances. The liquid drive rate increases by increasing the level of liquid in the suction chamber, as well as gas velocity. According to Balamurugan et al. [1], a critical parameter is the ratio of the throat cross section to the nozzle cross sectional area. Further investigation by considering gas holdup, mass transfer coefficient and interfacial area found that the coefficient of mass transfer and interface area increase as gas velocity is increased [2]. Another literature noted that surface roughness of material and geometries of components are to be an important aspects in ejector performance [3-4].

Numerical investigation of the entrainment behaviour and performance of gas-liquid ejectors highlighted that the length of the mixing pipe has proven to be an important design factor and can affect ejector performance significantly [5-6]. Moreover, both jet dynamics and jet break up phenomena are to be interesting aspects for advanced investigation as carried out by Sharma et al. [7]. Hydrodynamic properties including pressure drop, phase hold and pressure profile boost the jet ejector design correlations.

Although the ejector has a simple construction, it is still an interesting topic for further study. In association with the experiment carried out by Sugati et al. [8-9], this paper focus on numerical studies of the liquid-gas ejector including mixing phenomena inside the throat section. 


\section{Computational Domain and Approach}

This numerical study considers an experimental model of liquid-gas ejector previously investigated by Sugati et al. [8], as illustrated in Figure 1. It consists of nozzle, suction chamber, throat and diffuser. The key dimensions are shown in table 1.

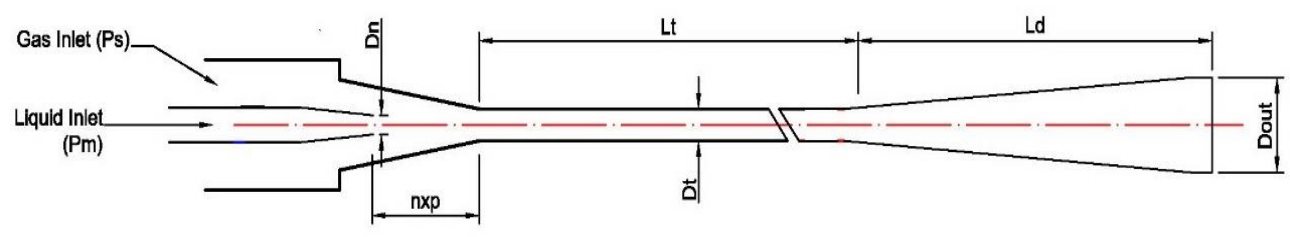

Fig. 1. Geometries of liquid-gas ejector.

Table 1. Dimension of liquid gas ejector

\begin{tabular}{clc}
\hline No & Components & Dimensions $(\mathrm{mm})$ \\
\hline 1 & Nozzle diameter $\left(\mathrm{D}_{\mathrm{n}}\right)$ & 12 \\
2 & Nozzle-Throat distance $(\mathrm{nxp})$ & 48 \\
3 & Throat diameter & 20 \\
4 & Throat length $\left(\mathrm{L}_{\mathrm{t}}\right)$ & 600 \\
5 & Diffuser length $\left(\mathrm{L}_{\mathrm{d}}\right)$ & 480 \\
6 & Diffuser outlet $\left(\mathrm{D}_{\text {out }}\right)$ & 60 \\
\hline
\end{tabular}

This computation used 415,000 hexahedra cells with high quality grids as indicated by $\Delta \mathrm{y}^{+}$ $<2$ at near wall resolution. Figure 2 shows the structured mesh of 2D computational domain behind the nozzle region. The realisable $\mathrm{k}-\epsilon$ turbulence model was chosen to simulate the turbulent flow inside the specimen. A finite volume method was applied to compute the governing equations. The second order upwind scheme was utilized for the momentum, turbulence kinetic energy and turbulence energy dissipation rate. The FLUENT commercial CFD package was used to resolve its equation.

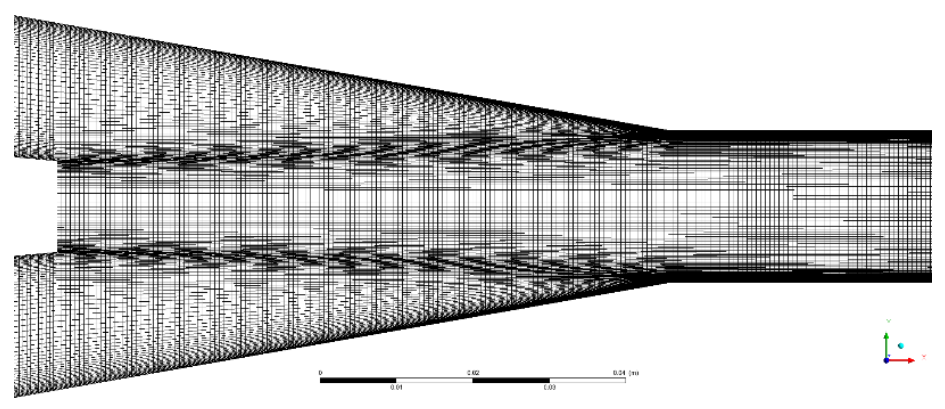

Fig. 2. Structured mesh of 2D computational domain around the nozzle area.

Initial flow and boundary conditions use the same values as previously applied in the experiment by Sugati et al. [8]. It can be seen in table 1. 
Table 2. Boundary conditions

\begin{tabular}{rll}
\hline No & Boundary condition & Detail \\
\hline 1 & Liquid (water) & $2-10 \mathrm{~m} / \mathrm{s}$ \\
2 & Gas (air) & $0.02 \mathrm{~m} / \mathrm{s}$ \\
3 & Outflow & atmospheric pressure \\
\hline
\end{tabular}

\section{Results and Discussion}

Both figure 3 and 4 represent the CFD predicted data of mixing characteristic along the liquid and gas ejector from throat to diffuser, at various liquid velocities from $u_{g}=2-10 \mathrm{~m} / \mathrm{s}$. This prediction was simulated at fixed fluid velocity of $0.02 \mathrm{~m} / \mathrm{s}$.

Figure 3(a) gives the validation data of pressure distribution along the throat section at near wall compared to the experimental data. In general, the trend of predicted data is consistent to the previous studies with realistic discrepancies, mainly behind the nozzle area.

Figure 3(b) shows the distribution of mixing pressures along the centre line of specimen, at different liquid velocities. The pressures increase rapidly with specific peak point in front of nozzle $\left(-2.5<\mathrm{x} / \mathrm{D}_{\mathrm{t}}<5\right)$, then it reduces gradually along the throat section before approaching the diffuser section. The increase of liquid speed causes the reduced maximum overshoot of pressure before going decay inside the throat section. The changes of the peak point data are seen more clearly at every multiple of the liquid velocities. Rapid increase of pressure at diffuser section is due to the enlargement of diffuser $\left(x / D_{t}>30\right)$. By keeping the same gas velocity at $0.02 \mathrm{~m} / \mathrm{s}$, the increase of liquid velocities is to be in lower level in terms of the pressure characteristic as clearly shown for $U_{\text {water }}=10 \mathrm{~m} / \mathrm{s}$.

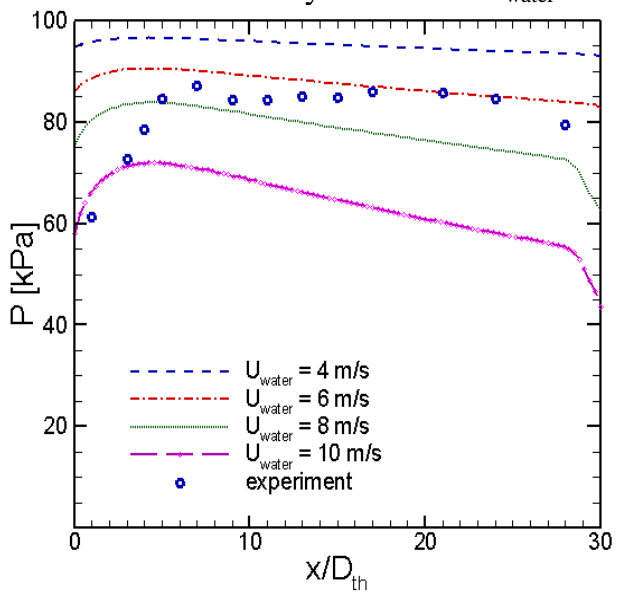

(a) near wall

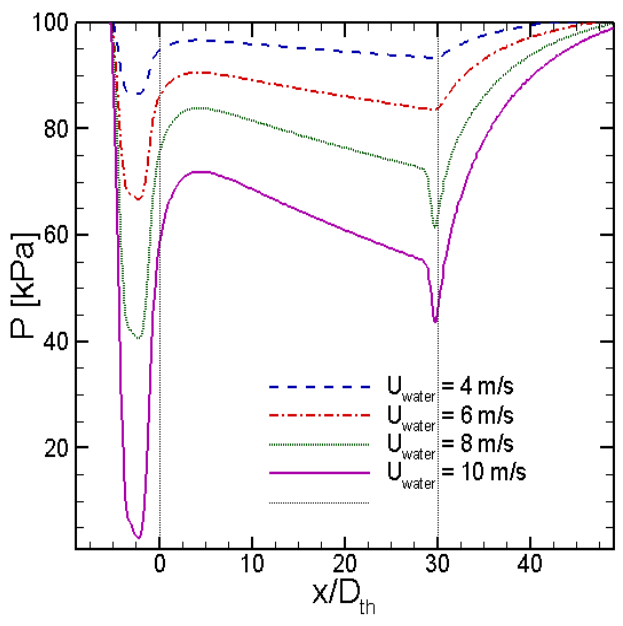

(b) centre position

Fig. 3. The pressure characteristics of liquid-gas mixing

In terms of the velocity characteristics of mixing flow, its drop rapidly in the region in front of the nozzle as illustrated in Figure 4. The decay of flow velocity at centre line position is shorter at lower liquid speeds. The turbulent kinetic energy produced by the liquid nozzle was distributed throughout the ejector. The jet envelope induces a higher gas induction with the air. 
The velocities of mixing gas tend to in a certain level with a smooth increase before decaying in the diffuser region.

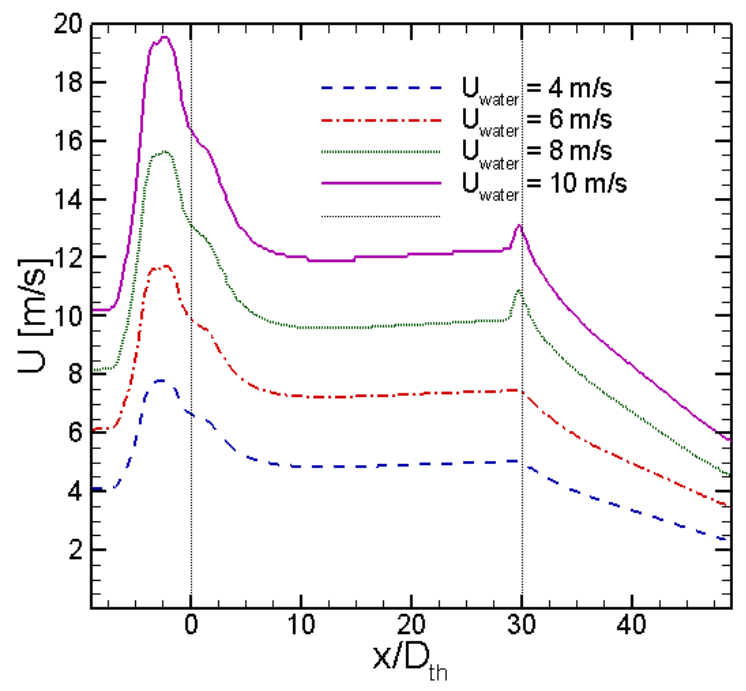

Fig. 4. The velocities profiles of liquid-gas mixing at the centre position.

Figure 5 provides the contour plot of pressure and velocity at the setting of liquid velocity = $10 \mathrm{~m} / \mathrm{s}$ with a fixed gas velocity of $0.02 \mathrm{~m} / \mathrm{s}$. It demonstrates that the maximum flow velocity occurs at the exit of the primary compressor nozzle (see Figure 5(b)), after which the velocity decreases due to the change of momentum and the mixing with the secondary fluid stream.

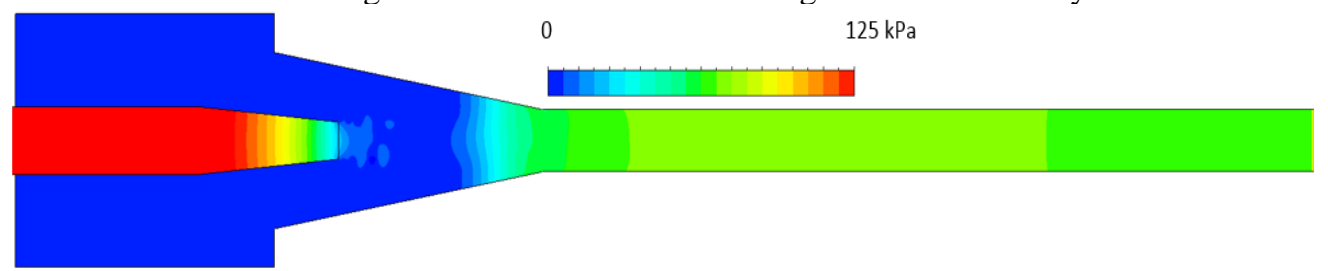

(a). Pressure profile

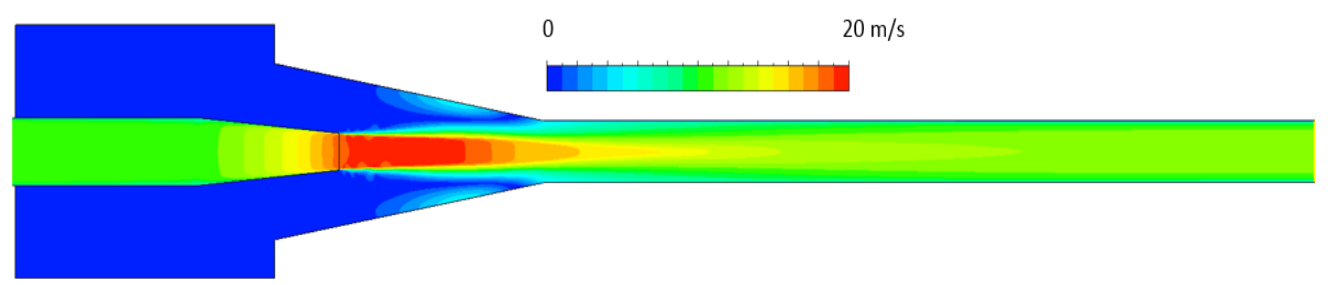

(b). Velocity profile

Fig. 5. Fields of mixing flow at the centre plane.

\section{Conclusion}


The distribution of pressure and velocity inside the liquid-gas ejector has been studied numerically. The mixing coefficient on the gas induction causes the mixing process as well as on the phase and velocity flow profiles within the ejector. The use of realisable k- $\epsilon$ turbulence model in the present study is capable of predicting correct trend compared to the available experimental data.The ratio between gas and liquid at the inlet flow is to be sensitive against the distribution of pressure and velocity along the liquid-gas ejector.

\section{Acknowledgment}

The authors would like to acknowledge the financial from Indonesian Government in supporting the research through Institut Teknologi Nasional Yogyakarta under PKLN project No 227/SP2H/LT/DRPM/2019; B/1436.17/L5/RA.00/2019;

01.b/ITNY/LPPM/

Pen.DRPM/IV/2019

\section{References}

[1] Balamurugan, S., Gaikar, V. G., \& Patwardhan, A. W. (2006). Hydrodynamic characteristics of gas-liquid ejectors. Chemical Engineering Research and Design, 84(12), 1166-1179.

[2] Balamurugan, S., Lad, M. D., Gaikar, V. G., \& Patwardhan, A. W. (2007). Hydrodynamics and mass transfer characteristics of gas-liquid ejectors. Chemical Engineering Journal, 131(1-3), 83-103.

[3] Song, X., Cao, M., Shin, W., Cao, W., Kang, S., \& Park, Y. (2014). Numerical investigation of a liquid-gas ejector used for shipping ballast water treatment. Mathematical Problems in Engineering, 2014.

[4] Yuan, G., Zhang, L., Zhang, H., \& Wang, Z. (2011). Numerical and experimental investigation of performance of the liquid-gas and liquid jet pumps in desalination systems. Desalination, 276(1-3), 89-95.

[5] Li, C., \& Li, Y. Z. (2011). Investigation of entrainment behavior and characteristics of gas-liquid ejectors based on CFD simulation. Chemical Engineering Science, 66(3), 405416.

[6] Li, C., Li, Y., \& Wang, L. (2012). Configuration dependence and optimization of the entrainment performance for gas-gas and gas-liquid ejectors. Applied Thermal Engineering, 48, 237-248.

[7] Sharma, D., Patwardhan, A., \& Ranade, V. (2018). Effect of turbulent dispersion on hydrodynamic characteristics in a liquid jet ejector. Energy, 164, 10-20.

[8] Sugati, D., Indarto, Purnomo, Sutrisno, Effendy, M., \& Yawara, E. (2018, July). Identification performance of the liquid-gas ejector using static pressure distribution. In AIP Conference Proceedings (Vol. 1983, No. 1, p. 020013). AIP Publishing.

[9] Sugati, D. (2014). Performance of Conical Diffuser on Liquid Jet Gas Ejector. In Applied Mechanics and Materials (Vol. 493, pp. 145-150). Trans Tech Publications 